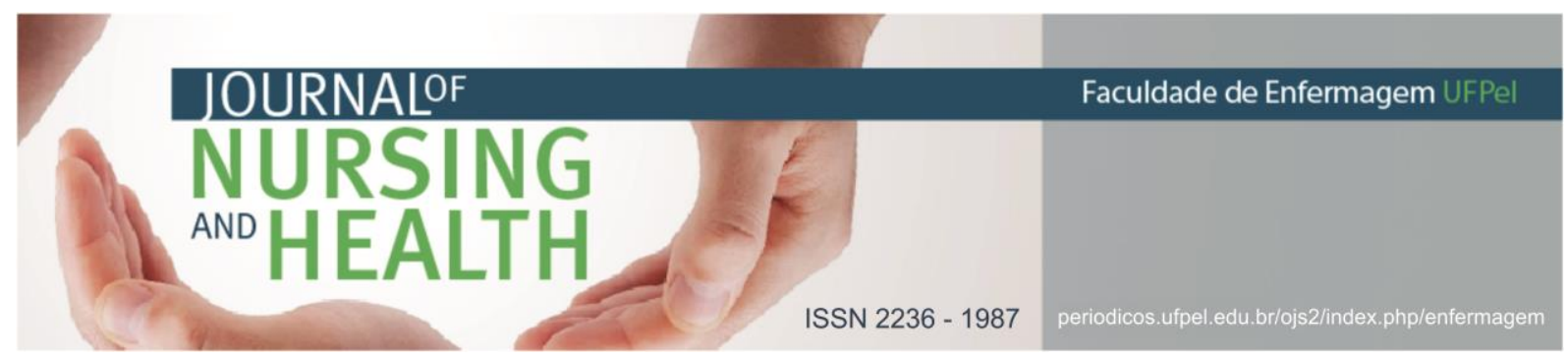

ENTREVISTA NARRATIVA

\title{
A experiência de um pós-doutorado e sua interface com a temática de ouvidores de vozes: entrevistando uma pesquisadora da área de enfermagem e saúde mental
}

The experience of a postdoctoral and its interface with the theme of voice hearers: interviewing a researcher in the nursing and mental health area

La experiencia de un postdoctorado y su interfaz con la temática de oyentes de voces: entrevistando a una investigadora del área de enfermería y salud mental

Gabriela Lobato de Souza1; Afra Suelene de Sousa²

Como citar este artigo: Souza GL, Sousa AS. A experiência de um pós-doutorado e sua interface com a temática de ouvidores de vozes: entrevistando uma pesquisadora da área de enfermagem e saúde mental. J. nurs. health. 2018;8(n.esp.):e188427

Palavras-chaves: Saúde mental; Ouvir vozes; Vivências.

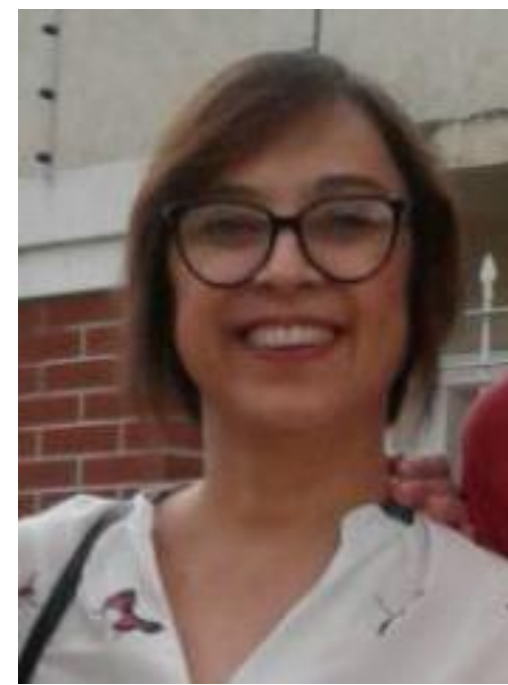

\section{APRESENTAÇÃO}

A presente entrevista foi produzida durante 0 I Congresso Nacional de Ouvidores de Vozes realizado pelo Instituto de Psiquiatria da Universidade Federal do Rio de Janeiro (IPUB/UFRJ) de 20 a 21 de outubro de 2017. Luciane é enfermeira e, atualmente, é Professora titular da Universidade Federal de Pelotas (UFPEL) e coordenadora adjunta da área de Enfermagem na Coordenação de Aperfeiçoamento de Pessoal de Nível Superior (CAPES). Tem experiência na área de Enfermagem, com ênfase em Avaliação de serviços de saúde mental. Realizou pósdoutorado na Università degli Studi di Torino (Estágio Sênior no exterior com fomento da (APES) sob acompanhamento do Prof. Mario Cardano o período de 1 de fevereiro de 2015 a 31 de janeiro de 2016.

\footnotetext{
1 Enfermeira. Mestre em Política Social. Instituto Federal Sul Rio-Grandense (IFSUL). E-mail: gaby_lobato@yahoo.com.br http://orcid.org/0000-0003-3415-588X

2 Enfermeira. Doutora em Educação. Universidade Federal de Pelotas (UFPEL). E-mail: afrasus@uol.com.br http: / /orcid.org/0000-0001-9636-4762
} 


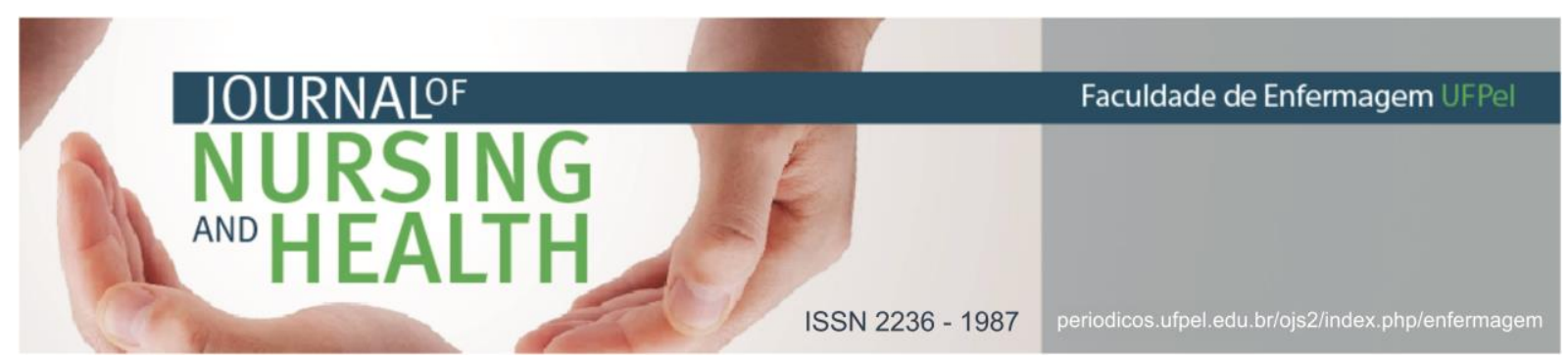

A trajetória acadêmica e a interface com a temática ouvidores de vozes

Meu nome é Luciane Prado Kantorski, tenho 52 anos, sou enfermeira e professora da Universidade Federal de Pelotas. Comecei a ouvir falar um pouco sobre os ouvidores de vozes em 2013 e 2014. Em 2013 ouvi falar que tinha todo esse movimento que iniciou na Holanda.

Eu sou professora da universidade, enfermeira, trabalho na área de saúde mental a mais de 30 anos, mas toda a tradição nossa é dentro do conhecimento da psiquiatria tradicional e a compreensão das vozes como sintoma como uma alucinação, e aí veio uma outra corrente que é o movimento de ouvidores de vozes que introduz o pensamento das vozes como uma experiência humana. Então essa perspectiva de entender o ouvir vozes como uma variação humana, como seria uma outra, como por exemplo ser um canhoto, é a perspectiva que vai ser introduzida a partir do movimento.

Depois que tive contato com o livro "Udire la voce degli dei: l'esperienza del Gruppo voci"1 que é do professor Mário Cardano (Professor ordinário da Universidade de Turim), e comecei a fazer alguns contatos com ele com vista a fazer meu pós-doutorado em Turim, na Itália. Na época eu tinha interesse particular em ir para Itália, primeiro, por conta da história da saúde mental que há mais de 30 anos terminou com o hospital psiquiátrico e criou outras formas de atenção, e segundo, para conhecer dentro desse contexto, transcorrido todo esse tempo, que perspectivas, que formas de cuidado, que estratégias de cuidado foram se consolidando, foram se constituído nesse campo da desinstitucionalização da saúde mental.

Por isso que eu me aproximei dos projetos como o "diálogo aberto", como dos "ouvidores de vozes". Nessa perspectiva de diminuir e até não consumir medicação psiquiátrica, de programas de redução de danos em relação ao consumo de psicofármacos. Então, por isso que eu também me aproximei dessas possibilidades e acompanhei o projeto lá em Settimo Torinese que é uma localidade italiana da região de Piemonte, província de Turim na Itália. E mesmo depois quando acompanhei o trabalho da Associação Matti a Cotimo e da organização dos usuários de saúde mental chamada Mad Pride, o fiz porque eram possibilidades de se cuidar e se pensar a saúde mental em uma outra perspectiva, num campo “desinstitucionalizante". Então, antes mesmo de eu ir para o pós-doutorado em 2015 eu me aproximei disso, e fui para esse lugar com essa perspectiva.

Quando eu cheguei na Itália, em janeiro de 2015, a minha perspectiva era ficar um ano, até fevereiro de 2016, e foi o que ocorreu. Então, comecei a frequentar um grupo de ouvidores de vozes de Settimo Torinese e nesse percurso durante as minhas conversas com o professor Mário Cardano eu fui até Albinea que é uma comuna italiana em Emília-Romana,e lá conheci a 


\section{NURSING \\ AND

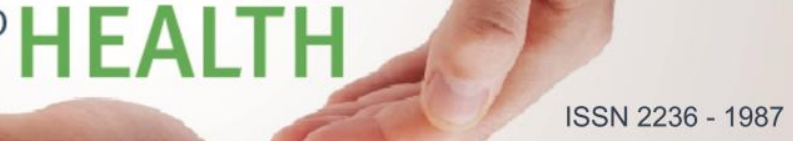

Cristina Contini, que é uma ouvidora de vozes, muito conhecida na Itália. A Cristina Contini tem 51 anos e nunca foi capturada pelo sistema psiquiátrico, é uma ouvidora de vozes desde jovem e constituiu estratégias para lidar com essas vozes dando significado para o que elas falavam sobre ela mesma ${ }^{2}$. Dentro dessa perspectiva, junto com o Mario Cardano, o Marcello Macario um psiquiatra facilitador de um grupo de Ouvidores de Vozes na região de Savona, e outras pessoas foi criada uma associação, foi feito o Congresso de ouvidores de vozes também na Itália, em Savona.

$\mathrm{Na}$ Itália esse percurso vai se disseminar, na verdade, a partir de 2011 com a criação da rede "Parlare con le voci" que é uma rede associada a International Hearing Voices Projects (INTERVOICE) mas que também ali tem todos os cursos, todos os grupos de ouvidores de vozes que funcionam na Itália. A Itália hoje tem cerca de 30 grupos de auto mútuo ajuda de ouvidores de vozes e eles realizaram outros dois congressos porque também o movimento ele não trabalha só com a questão dos grupos. Ele trabalha com a questão dos grupos, com a questão da formação com a organização de um congresso internacional. Ele trabalha com várias frentes porque ele não se reduz a questão do grupo porque é necessário disseminar uma outra forma de pensar em relação as vozes, e isso precisa de um trabalho mais amplo.

Eu me aproximei da Cristina Contini, fiz dois cursos de formação com ela, sobre a questão dos ouvidores de vozes, depois acompanhei o grupo do Marcello Macário, que é um psiquiatra, de Savona em San Giuseppe di Cairo, acompanhei o grupo de ouvidores de vozes lá, e assim foi meu encontro inicial com esse tema, que foi uma coisa muito interessante para mim.

A aproximação com a Cristina Contini, os cursos que fiz, tudo isso teve um grande impacto para mim em relação a discussão dos ouvidores de vozes. Essa perspectiva de vivenciar o tema como uma experiência mudou muita coisa para mim enquanto pessoa e, também, como uma trabalhadora no campo da saúde mental.

A história da Itália eu não vou contar, mas a gente sabe que essa experiência está enraizada em um lugar onde não se tem manicômios há 30 anos, então isso também faz uma diferença. Eu acompanhei estas experiências de março de 2015 até janeiro de 2016. Os grupos de ouvidores de vozes basicamente de Settimo Torinese e de San Giuseppe di Cairo. Os pressupostos dos grupos se delimitam a partir da expertise da experiência do sujeito que ouve vozes e da abordagem das vozes como uma experiência singular. O conceito de expertise por experiência está cada vez mais disseminado no mundo. Para mim é importante pensar que eu sou uma enfermeira e que tenho uma expertise por ciência que é aquela conferida pelos bancos da universidade, pelas experiências que eu vivi nos serviços, pela sistematização que eu fiz como pesquisadora. E que o ouvidor de vozes tem uma expertise por experiência que eu não tenho, que é aquela de ouvir as vozes que outros não ouvem. Isso para 


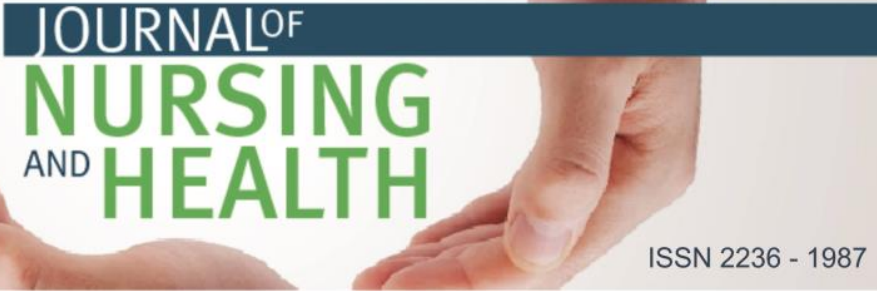

mim foi muito importante e me mudou na verdade. $E$ o que foi determinante para essa mudança foi uma formação que eu fiz com a Cristina Contini que é escritora desse livro "Sentire le voci" que está sendo lançado em português com o título "Ouvir vozes" neste Congresso. Algo que consegui entender foi o como era diferente quando um ouvidor de vozes falava com outro ouvidor. Durante um dos cursos uma mãe de um adolescente falou: "Eu demorei muito para entender que as vozes do meu filho não eram reais e pertenciam ao mundo dele" E a Cristina Contini respondeu: "As vozes são reais". Então eu penso que durante esse curso eu consegui entender um pouco melhor o que é isso, pensar o quanto estas vozes são reais no interior desta experiência, o que para mim não é um deslocamento fácil porque eu sou uma profissional da saúde e esta compreensão exige um outro tipo de movimento. Então eu penso que aquela experiência assim um pouco mais próxima, que não foi necessariamente em grupo, mas num curso de formação ou até na experiência individual com pais e com ouvidores de vozes, provocou muitas mudanças. Por isso para trabalhar com essa temática, em algum momento muda o modo de pensar da pessoa.

O outro pressuposto dos grupos de ouvidores é de que é possível criar estratégias para lidar com as vozes, que é necessário romper com os estigmas que vem da leitura psiquiátrica, então é preciso romper com essa noção de sintoma e assumir uma noção de experiência, numa perspectiva fenomenológica.

O grupo é um espaço para compartilhar experiências de ouvir vozes, para compreender a experiência, para desenvolver estratégicas de enfretamento $e$ principalmente para que a pessoa volte a protagonizar sua própria vida. Porque ela assumindo esse controle sobre a sua vida, além da experiência das vozes ou com a experiência das vozes, ela se torna o sujeito da sua própria vida e de suas próprias escolhas. O grupo é um lugar seguro para falar sobre as vozes, é um local de descoberta de significados, onde a pessoa busca alcançar o controle da experiência, é um espaço de construção de redes sociais bem importante e é um ambiente para a pessoa se desenvolver enquanto agente transformador na sua vida e na vida de outros membros do grupo.

Estas experiências permitiram que no retorno do pós-doutorado, nosso Grupo de Pesquisa em Enfermagem em Saúde Mental e Saúde Coletiva da UFPEL trabalhasse na organização de duas disciplinas na pós-graduação sobre este tema, numa delas tivemos cerca de 70 pessoas que frequentaram regularmente, entre elas, profissionais dos serviços de atenção psicossocial, estudantes, ouvidores de vozes. Também introduzimos o tema no nosso currículo de graduação do Curso de Enfermagem da UFPEL, realizamos seminários abertos para debater o tema, estamos realizando uma pesquisa caracterizando ouvidores, as vozes e conhecendo mais profundamente estas experiências, formamos um grupo de ouvidores de vozes em Pelotas e temos assessorado os municípios vizinhos em suas iniciativas. Foram muitas as 
possibilidades que se desenharam a partir do contato com a perspectiva de reconhecer o ouvir vozes como uma experiência e tantas outras deverão surgir neste caminho.

\section{REFERÊNCIAS}

1 Cardano M; Lepori G. Udire la voce degli dei. L'esperienza del gruppo voci. Milano: Franco Angeli; 2012.

2 Kantorski LP; Andrade APM de; Cardano M. Estratégias, expertise e experiências de ouvir vozes: entrevista com Cristina Contini. Interface comun saúde educ [Internet]. 2017 [acesso em 2018 set 10];21(63):1039-48. Disponível em: http://www.scielo.br/pdf/icse/v21n63/1807-5762-icse-21-63-1039.pdf

Data de publicação: 19/09/2018 